\title{
A Simplified Hybrid Model For Cyclic Loaded Strip Footing On The Granular Materials
}

\author{
Muhittin Babaoglu ${ }^{1,2}$, H. Ercan Tasan ${ }^{3}$, Sinan Turhan Erdogan ${ }^{1}$ \\ ${ }^{1}$ Civil Engineering Department/Middle East Technical University \\ Ankara, Turkey \\ muhittin.babaoglu@metu.edu.tr; \\ ${ }^{2}$ Civil Engineering Department/Konya Technical University \\ Konya, Turkey; \\ ${ }^{3}$ Civil Engineering Department/Ankara Y1ldırım Beyazıt University \\ Ankara, Turkey
}

\begin{abstract}
This paper describes a simplified hybrid model implemented using the finite element method (FEM) that can be used to estimate the displacements of strip footing subjected to a high number of load cycles. The simplified model comprises a classical constitutive approach, where load cycle is progressively computed using FEM, and an empirical formulation, which analytically calculates accumulation of strain for a targeted number of load cycles in one increment of finite element analysis (FEA). The model demands less time and computational resources. In addition, the accumulated error by-product of complete analysis is minimal, thanks to the empirical formulation. For calibration, the model needs a few static and cyclic triaxial tests. In this study, the model is validated using an axially cyclic loaded 3D strip footing on sand. Results suggest improved predictions with higher magnitudes of load cycles.
\end{abstract}

Keywords: Cyclic loading, Strain accumulation, Finite element method, Simplified model, Granular materials

\section{Introduction}

In granular materials, repeated cycles bring about strain accumulation with each cycle of loading. This phenomenon entails a broad range of issues in structures that interact with granular materials and are subjected to cyclic loading, e.g., highway and railway structures, foundations of offshore wind turbines and oil platforms, onshore wind turbines, machine foundations, cyclically hydrostatic loaded structures. For instance, differential settlement caused by cyclic loading is an infamous failure type in pavements, machine foundations, and buildings [1], [2]. Another example is pavement rutting due to the repeated loading of vehicles [3].

Nevertheless, the above-mentioned high number of load cycle problems make the experimental testing of strain accumulation costly and time-consuming. Thus, the numerical prediction of permanent strain accumulation is crucial for design. In addition, internal factors (material related) such as moisture content, relative density, drainage condition, permeability, stress history, aggregate shape, strength, and size distribution and external factors such as loading amplitude, frequency, and type (one-way or two-way) contribute to the complex behavior of cyclic loaded granular materials [4]-[7]. There are three types of strain accumulation estimation approaches in the literature: Mechanical models based on classical constitutive models, analytical models that are observation-based approaches, and shakedown theory [8].

Mechanical models, which could be based on different types of material models, have a stress-strain constitutive relation that incrementally calculates the cyclic response of granular materials using the finite element method [9]-[11]. However, they require an enormous amount of computational resources and time to analyze a complex 3D geometry with a high number of repeated load cycles. Moreover, error accumulates by-products of finite element analysis for each load cycle, and over a certain number of cycles, the cumulative error is magnified by the number of load cycles that deviate results [12].

Analytical models, based on empirical functions that provide the relation between strain accumulation and the number of load cycles, are another approach that utilizes an empirical relation based on the correlation determined from laboratory testing. This relation depends on external and internal factors of granular materials. In the 1960s and 1970s, researchers offered prediction models built upon cyclic triaxial tests to analytically calculate permanent deformation of unbound granular materials in pavement design [13], [14]. Since then, numerous relationships have been presented to estimate strain 
accumulation empirically [15]-[17]. Lastly, shakedown theory approaches assert whether the stress level in granular materials is above or below certain thresholds that allow determining whether permanent deformation of strain accumulation will be stable at the end of a specified number of cycles [7], [18]-[20].

Furthermore, researchers have combined mechanical models with analytical models as hybrid models [21]-[24]. In this study, a simplified hybrid model initially proposed for cyclic loaded monopile foundations is implemented using FEM to predict the strain accumulation behavior of cyclic loaded granular materials under a strip footing.

\section{Material Model}

The implemented model in this study, the "Explicit Cyclic Duncan Chang" model (ECDC), is a simplified hybrid model of a classical constitutive model and an analytical model [25], which is developed from preceding studies [21][24]. As a mechanical model, it computes the first cycle; then, it uses an empirical function to calculate strain accumulation up to the targeted loading cycle as an analytical approach. In this study, the model is implemented and validated using experimental data for granular materials under a cyclic loaded strip footing. The model comprises the first cycle, cyclic accumulation, and the last cycle stages, illustrated in Fig. 1.

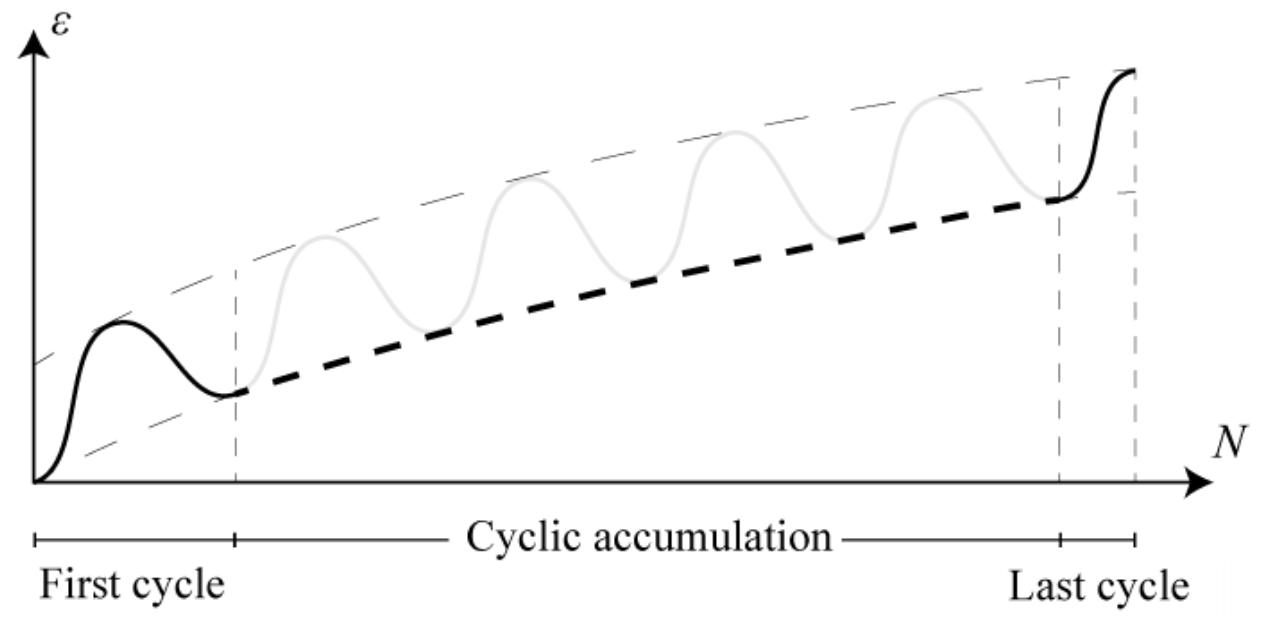

Fig. 1: Stages of the model.

The strain is decomposed as $\varepsilon=\varepsilon_{e}+\varepsilon_{p}$ in three-dimensional space where $\varepsilon$ is the strain tensor, $\varepsilon_{e}$ is the elastic strain tensor, and $\varepsilon_{p}$ is the tensor stores strain accumulation. Isotropic strain accumulation assumption is made as other studies suggested [21]. Incremental stress form is implemented as $d \sigma^{n+1}=C:\left(d \varepsilon^{n+1}-d \varepsilon_{p}^{n}\right)$ where $d \sigma^{n+1}, C, d \varepsilon_{p}^{n}$ are the stress increment, stiffness tensor, and strain accumulation of the cyclic loading, respectively.

In the first cycle stage, which consists of monotonic loading and then monotonic unloading, Duncan \& Chang model $(D \& C)$ is utilized as constitutive relation [26]. When monotonic loading and monotonic unloading steps are completed, the permanent strain of the first cycle $\left(\varepsilon_{p, N=1}\right)$ is obtained for the calibration of the mathematical function of strain accumulation [24]. Parameters of the D\&C are obtained from static triaxial tests.

The second stage of the model is the cyclic accumulation, in which strain accumulation of the rest of the cycles is computed based on the empirical function selected. In this paper, the $\log -\log$ approach $\varepsilon_{p, N}=a_{1} N^{a_{2}}$ where $N$ is the number of cycles, $a_{1}, a_{2}$ are constants, is employed [4], [6], [27], [28]. $a_{1}$ constant is equal to $\varepsilon_{p, N=1}$ which is calculated in the first cycle for every element of the domain. Moreover, it also inherently represents the direction of strain [24]. $a_{2}$ constant is moisture-dependent coefficient [28], and it does not change with the applied stress [15]. This coefficient is determined from cyclic triaxial tests [4], [28]. 
The third stage is called the last cycle, in which D\&C with reloading modulus is implemented to obtain total strain. Employing constitutive relation subsequently to the cyclic accumulation step redistributes stresses in the boundary value problem [12].

\section{Results}

The model is implemented in an experimental study [11] in which a 3D strip footing on granular materials is subjected subjected to cyclic loading. A $0.2 \mathrm{~m}$ wide and $1 \mathrm{~m}$ long rigid strip footing rests on granular materials in a $2 \mathrm{~m} \times 1 \mathrm{~m} \times 1 \mathrm{~m}$ $m$ rectangular box. A cross-section is shown in Fig. 2, and a 3D view is given in Fig. 3 [11].

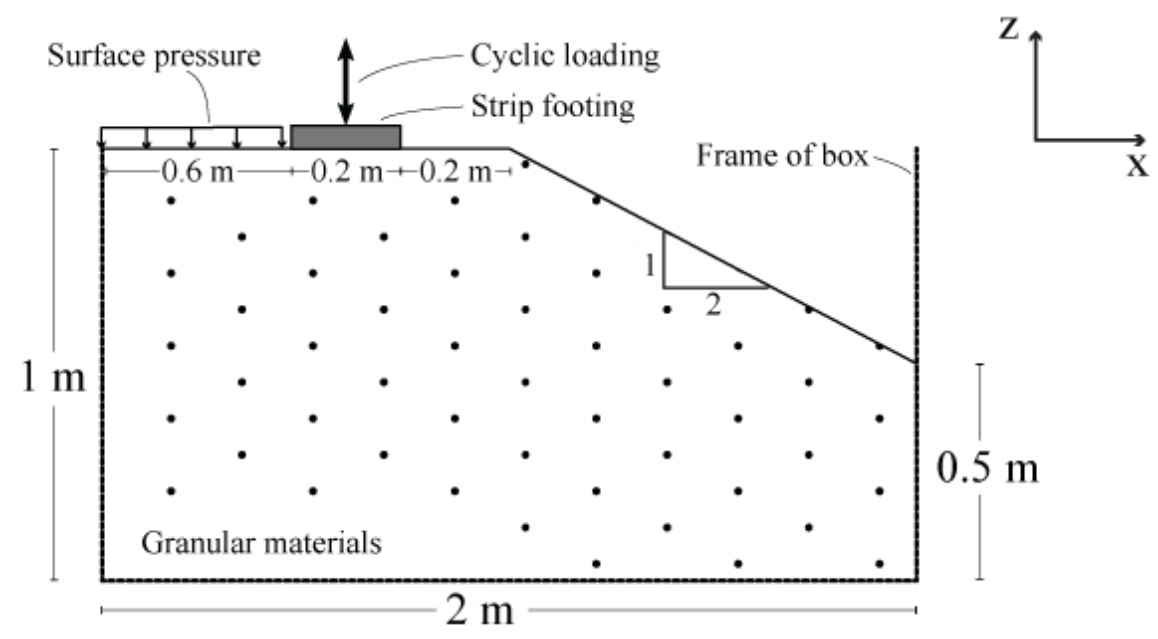

Fig. 2: Cross-section view of strip footing on the granular materials.

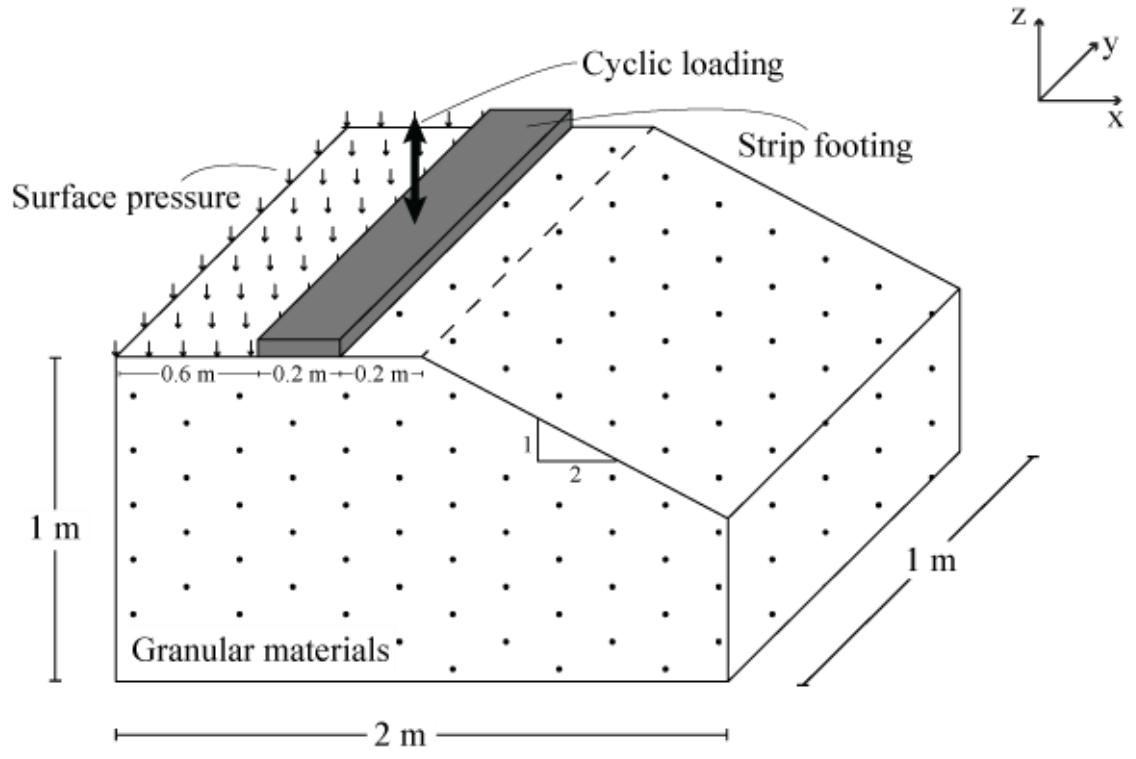

Fig. 3: 3D view of strip footing on the granular materials.

Stress-controlled cyclic loading is applied to the strip footing in the z-direction. Vertical and horizontal displacements are measured on the strip footing. There is a slope of granular materials with $2 \mathrm{H}: 1 \mathrm{~V}, 0.2 \mathrm{~m}$ away from the footing, as shown 
in Fig. 2. In addition, a constant $8 \mathrm{kPa}$ surface pressure is applied on the other side of the footing. The strip footing is loaded with three different cyclic loading combinations, $18-30 \mathrm{kN}, 27-45 \mathrm{kN}, 36-60 \mathrm{kN}$, as trough and crest amplitude of the cycles, respectively. It is loaded for 1000 cycles in the z-direction for each load combination.

Granular materials under the strip footing are compacted at maximum dry density with optimum water content, $\mathrm{kg} / \mathrm{m}^{3}$, and $4.75 \%$, respectively. The tested granular material parameters, which is well-graded sand, are given in Table [11].

\begin{tabular}{cccccccc}
\multicolumn{8}{c}{ Table 1: D\&C parameters of the granular material [11] } \\
\hline Compaction level & $\Phi$ & $R_{f}$ & $K$ & $K_{u r}$ & $n$ & $n_{u r}$ & $c(\mathrm{kPa})$ \\
Maximum dry density & 44 & 0.88 & 2000 & 2910 & 0.62 & 0.4 & 8.2 \\
\hline
\end{tabular}

The same granular materials with the same parameters are used for monotonic and cyclic triaxial tests and the rectangular box test [11]. The coefficient $a_{1}$ can be determined after the the first cycle, as mentioned previously. Since it is equal to the permanent strain after the first cycle, this parameter does not require an additional test. It is calculated during the analysis. On the other hand, To determine the coefficient $a_{2}$, several cyclic triaxial tests are required. The cumulative permanent strain to the number of load cycles plot is acquired from the tests. The least-squares fitting of the obtained data to the function $\varepsilon_{p, N}=a_{1} N^{a_{2}}$ provides $a_{2}$.

Since Alam et al. [11] named the first cycle $\mathrm{N}=0$, and in our model the first cycle is called $\mathrm{N}=1$, calculation of the coefficient $a_{2}$ for each provided cyclic triaxial test is processed accordingly. To be able to compare vertical settlement accurately, the least-square regression of $a_{2}$ is done by removing $\mathrm{N}=0$ cycle. From the cyclic triaxial tests $a_{2}$ is obtained as 0.063 , and it is utilized for the strip footing analysis.

\subsection{Settlement of the Strip Footing}

The granular material in the box shown in Fig. 3 meshed with 10-node tetrahedral elements, and the material model is assigned to these elements. The tetrahedral element is preferred over the hexahedral element due to the presence of a slope in the geometry. The $0.2 \mathrm{~m}$ wide steel strip footing is meshed with the same element type by assigning a linear elastic model. Granular materials at the side of the box are fixed horizontally, whereas materials at the bottom of the box are vertically constrained. For the model, a constant $8 \mathrm{kPa}$ surface pressure is placed at the exact location as in the experimental test. The rigid strip footing is supported horizontally, and it is vertically cyclic loaded with three different load patterns, $18-30 \mathrm{kN}, 27-45 \mathrm{kN}, 36-60 \mathrm{kN}$.

In the initial step, gravitational acceleration is applied to take into account the weight of granular materials. Then, the load is incrementally applied to the strip footing up to the maximum value $(30,45$, or $60 \mathrm{kN})$. Subsequently, the strip footing is unloaded to zero. In the following stage, the strain accumulation step is initialized with the same boundary conditions as in the previous step. Finally, to determine total strain, the strip footing is reloaded up to the minimum loading value $(18,27$, or $36 \mathrm{kN})$.

The vertical settlement of the strip footing in the experimental test is compared with the settlement predicted by the model. The vertical settlement, which is the permanent displacement of granular materials in the z-direction, is normalized by dividing the width of the strip footing to obtain $\delta_{\mathrm{v}} / \mathrm{B}$ in which $\delta_{\mathrm{v}}$ is the vertical settlement, B is the width of the footing. The three loading combinations are provided in Fig. 4, where the experimental test results are labeled "Experiment-X-Y," and the analysis results are tagged "ECDC-X-Y." X represents the minimum load and, Y represents the maximum load. 


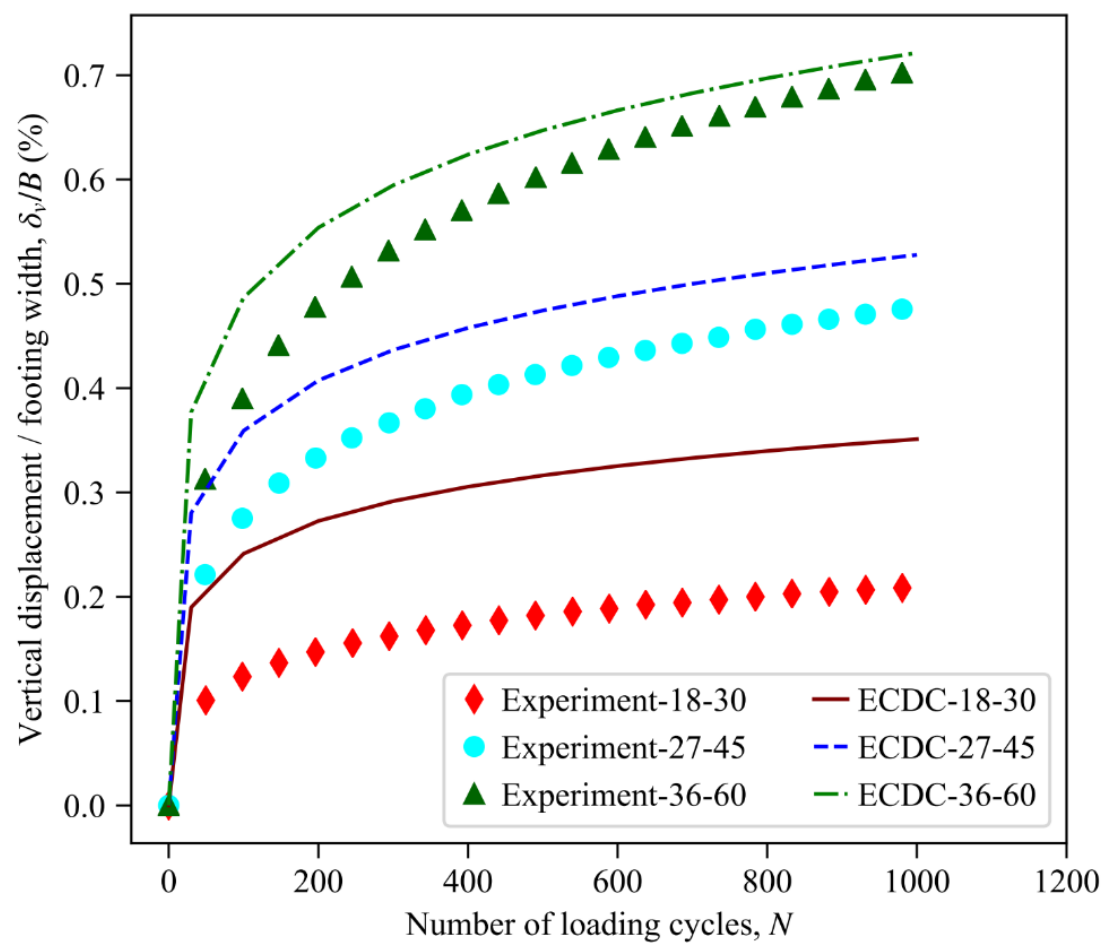

Fig. 4: The model prediction vs. experimental results

It is observed that $\delta_{v} / B$ is substantially dependent on the applied load, and it increases with the magnitude of the applied load. Moreover, the shapes of the model predicted curves match the experimental ones. As the empirical log-log approach predicts that acceleration of the increase in $\delta_{v} / B$ exponentially decreases with the increasing number of cycles. Furthermore, the model's prediction improves as the number of cycles increases for all three cases. For instance, at $\mathrm{N}=500, \mathrm{ECDC}-18-30$ is $74 \%$ above the experiment result, whereas it predicts $68 \%$ above the experiment at $\mathrm{N}=1000$. At $\mathrm{N}=500, \mathrm{ECDC}-27-45$ is $15 \%$ above the experiment whereas it forecasts $11 \%$ above the experiment at $\mathrm{N}=1000$ and finally, at $\mathrm{N}=500$, ECDC$36-60$ is $8 \%$ above the experiment while it is $3 \%$ above the experiment at $\mathrm{N}=1000$. In addition, the model prediction is better at higher magnitudes of cyclic load.

\section{Conclusion}

A finite element implementation of a simplified hybrid model describing the strain response of granular materials under cyclic loaded strip footing is presented. The model takes advantage of both classical constitutive relations and empirical models. It requires less computational resources and takes less time since it calculates most of the cycles analytically. Moreover, the accumulated error by-product of complete analysis is minimal, thanks to the cyclic accumulation stage. In addition, it requires a few static and cyclic triaxial tests for calibration. The predictions of the model match well with the shape of the results of cyclic loaded 3D strip footing. Although the model can solve boundary value problems with a higher number of load cycles, it is tested with 1000 cycles in the strip footing example. In future studies, the simplified approach can be generalized, and it can be extended to include pore pressure accumulation during the cyclic loading.

\section{References}

[1] S. K. K. Hussaini, B. Indraratna, and J. S. Vinod, "Performance assessment of geogrid-reinforced railroad ballast during cyclic loading," Transp. Geotech., vol. 2, pp. 99-107, 2015, doi: 10.1016/j.trgeo.2014.11.002.

[2] T. Wichtmann, "Explicit accumulation model for non-cohesive soils under cyclic loading," PhD Thesis, Inst. für Grundbau und Bodenmechanik, vol. Phd, p. 274, 2005. 
[3] Y. Qiao, A. Dawson, A. Huvstig, and L. Korkiala-Tanttu, "Calculating rutting of some thin flexible pavements from repeated load triaxial test data," Int. J. Pavement Eng., vol. 16, no. 6, pp. 467-476, 2015, doi: 10.1080/10298436.2014.943127.

[4] H. E. Taşan, "Zur Dimensionierung der Monopile-Gründungen von Offshore-Windenergieanlagen," Universitätsbibliothek der Technische Universität Berlin, 2011.

[5] F. Lekarp, U. Isacsson, and A. Dawson, "State of the art. II: Permanent strain response of unbound aggregates," J. Transp. Eng., vol. 126, no. 1, pp. 76-83, 2000.

[6] G. T. H. Sweere, "Unbound granular bases for roads (Doctoral thesis)," Delft Univ. Technol. Netherlands, 1990.

[7] S. Werkmeister, A. R. Dawson, and F. Wellner, "Pavement design model for unbound granular materials," J. Transp. Eng., vol. 130, no. 5, pp. 665-674, 2004, doi: 10.1061/(ASCE)0733-947X(2004)130:5(665).

[8] G. Cerni, F. Cardone, A. Virgili, and S. Camilli, "Characterisation of permanent deformation behaviour of unbound granular materials under repeated triaxial loading," Constr. Build. Mater., vol. 28, no. 1, pp. 79-87, 2012, doi: 10.1016/j.conbuildmat.2011.07.066.

[9] C. Chazallon, P. Hornych, and S. Mouhoubi, "Elastoplastic model for the long-term behavior modeling of unbound granular materials in flexible pavements," Int. J. Geomech., vol. 6, no. 4, pp. 279-289, 2006, doi: 10.1061/(ASCE)15323641(2006)6:4(279).

[10] P. Hornych, A. El Abd, C. Chazallon, and F. Allou, "Prediction of Permanent Deformations of Unbound Granular Materials in Low Traffic Pavements," Road Mater. Pavement Des., vol. 8, no. 4, pp. 643-666, 2007, doi: 10.1080/14680629.2007.9690093.

[11] M. J. I. Alam, C. T. Gnanendran, and S. R. Lo, "Modelling the settlement behaviour of a strip footing on sloping sandy fill under cyclic loading conditions," Comput. Geotech., vol. 86, pp. 181-192, 2017, doi: 10.1016/j.compgeo.2017.01.010.

[12] T. Wichtmann, "Explicit accumulation model for non-cohesive soils under cyclic loading," Inst. für Grundbau und Bodenmechanik Braunschweig, Germany, 2005.

[13] J. H. Haynes, "Effects of repeated loading on gravel and crushed stone base course materials used in the $\{$ AASHO Road Test, Final Report, Joint Highway Research Project, Project: C-36-45H, File:6-18-8," Purdue University, 1961.

[14] R. D. Barksdale, "Laboratory evaluation of rutting in basecourse materials," in Third International Conference on the Structural Design of Asphalt Pavements, 1972, vol. 1, no. Proceeding, pp. 161-174.

[15] D. Li and E. T. Selig, "Cumulative plastic deformation for fine-grained subgrade soils," J. Geotech. Eng., vol. 122 , no. 12, pp. 1006-1013, 1996.

[16] H. G. Kempfert and Y. Hu, "Numerical modeling of the deformation in railway foundation - A case study," in Numerical models in geomechanics. Proceedings of the 7th international symposium, Graz, September 1999., 1999, pp. 669-674.

[17] G. Gidel, P. Hornych, J. J. Chauvin, D. Breysse, and A. Denis, "A new approach for investigating the permanent deformation behaviour of unbound granular material using the repeated loading triaxial apparatus," Bull. des Lab. des Ponts Chaussees, no. 233, 2001.

[18] S. Werkmeister, A. R. Dawson, and F. Wellner, "Permanent deformation behavior of granular materials and the shakedown concept," Transp. Res. Rec., vol. 1757, no. 1757, pp. 75-81, 2001, doi: 10.3141/1757-09.

[19] R. Garcia-Rojo and H. J. Herrmann, "Shakedown of unbound granular material," Granul. Matter, vol. 7, no. 2-3, pp. 109-118, 2005, doi: 10.1007/s10035-004-0186-6.

[20] F. Allou, C. Petit, C. Chazallon, and P. Hornych, "Shakedown approaches to rut depth prediction in low-volume roads," J. Eng. Mech., vol. 136, no. 11, pp. 1422-1434, 2010, doi: 10.1061/(ASCE)EM.1943-7889.0000165.

[21] A. S. J. Suiker and R. de Borst, "A numerical model for the cyclic deterioration of railway tracks," Int. J. Numer. Methods Eng., vol. 57, no. 4, pp. 441-470, 2003, doi: 10.1002/nme.683.

[22] A. Niemunis, T. Wichtmann, and T. Triantafyllidis, "A high-cycle accumulation model for sand," Comput. Geotech., vol. 32, no. 4, pp. 245-263, 2005, doi: 10.1016/j.compgeo.2005.03.002.

[23] S. François, C. Karg, W. Haegeman, and G. Degrande, "A numerical model for foundation settlements due to deformation accumulation in granular soils under repeated small amplitude dynamic loading," Int. J. Numer. Anal. 
Methods Geomech., vol. 34, no. 3, pp. 273-296, 2010.

[24] C. Pasten, H. Shin, and J. Carlos Santamarina, "Long-term foundation response to repetitive loading," J. Geotech. Geoenvironmental Eng., vol. 140, no. 4, pp. 1-11, 2014, doi: 10.1061/(ASCE)GT.1943-5606.0001052.

[25] M. Babaoglu, "Finite Element Implementation of a Model to Estimate the Permanent Strain of Cyclically-Loaded Soil (Master's thesis)," Middle East Technical University, 2020.

[26] J. M. Duncan and C.-Y. Chang, "Nonlinear analysis of stress and strain in soils," J. Soil Mech. Found. Div, vol. 5, pp. 1629-1653, 1970.

[27] A. Hettler and G. Gudehus, "Repetitive load deformation of cohesionless soil," J. Geotech. Eng., vol. 109, no. 12, pp. 1628-1630, 1983, doi: 10.1061/(ASCE)0733-9410(1983)109:12(1628).

[28] G. Behzadi and W. O. Yandell, "Determination of elastic and plastic subgrade soil parameters for asphalt cracking and rutting prediction," Transp. Res. Rec., vol. 1540, no. 1540, pp. 97-104, 1996, doi: 10.3141/1540-14. 